\title{
REAR SIDE CONSPICUITY OF HEAVY GOOD VEHICLES BASED ON LIGHTING COMPONENTS
}

\author{
Siti Aishah Yahya ${ }^{1}$, Nur Baitul Izati Rasli ${ }^{*}{ }^{凶}$, Nor Azam Ramli ${ }^{1}$, Syabiha Shith ${ }^{1}$ \\ ${ }^{* 1}$ Environmental Assessment and Clean Air Research, School of Civil Engineering, Engineering \\ Campus, Universiti Sains Malaysia, 14300, Nibong Tebal, Penang, Malaysia
}

DOI: https://doi.org/10.29121/ijetmr.v7.i9.2020.786

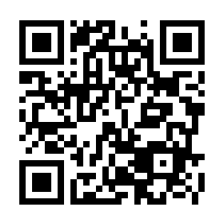

Article Citation: Siti Aishah Yahya, Nur Baitul Izati Rasli, Nor Azam Ramli, and Syabiha Shith. (2020). REAR SIDE CONSPICUITY OF HEAVY GOOD VEHICLES BASED ON LIGHTING COMPONENTS.

International Journal of Engineering Technologies and Management Research, 7(9), 72-79. https://doi.org/10.29121/ijetmr.v7 i9.2020.786

Published Date: 30 September 2020

Keywords:

HGVs

Road Accident

Road Transport Act

Un Regulations

Visibility

Warning System

\begin{abstract}
In Malaysia, accidents that involve collisions with rigid and articulated trucks are mainly related to the conspicuity issue i.e. the issue of the conspicuity of the lighting components on heavy goods vehicles (HGVs). Thus, visibility and conspicuity must be improved because such an improvement can help drivers encounter safety measures on the psychological phenomenon. Conspicuity is the ability of a vehicle to be noticed without observers intentionally searching for it. In Malaysia, HGVs must be equipped with lighting components for improved visibility. The study aims to analyse the percentages of lighting components that comply with the MS ISO 303:2004. This research is conducted at Jawi Toll Plaza, Nibong Tebal, Pulau Pinang from 9:00 a.m. to 5:00 p.m. Results show that 93\% of two-axle box trucks have installed rear lighting components that adhere to the standard. Meanwhile, other categories are between $38 \%$ and 91\%. In conclusion, even though Heavy Goods Vehicles recorded as having high compliance levels of the rear lighting components, the accident still occurred. The types of crashes are based on the inadequate visibility involved when the moving vehicles are approaching the rear or sides of slow-moving or stationary vehicles at night.
\end{abstract}

\section{INTRODUCTION}

Accidents that involve collisions with rigid and articulated trucks are related to the conspicuity issue, which is associated with the rear markings and light components on heavy goods vehicles (HGVs). Accident data recommend that the conspicuity of HGVs and the following distance are the main contributory factors in accident causation. Thus, visibility and conspicuity must be improved because both can help drivers encounter safety measures on the psychological phenomenon.

Underride crashes can be dangerous for passengers in vehicles that drive under trucks. Drivers should always control a safe distance between themselves and the HGVs ahead of them (Ashenden and Associates, 2018). In general, underride accidents occur when trucks move slowly or are in a static condition and are hit from behind by smaller vehicles, which cannot slow down and instead slide under trucks (Kirkendall, n.d).

This study evaluates the lighting components and analyses their percentages that are related to the conspicuity rear of HGVs that comply with MS ISO 303:2004.

(C) 2020 The Author(s). This is an open access article distributed under the terms of the Creative Commons Attribution License, which permits unrestricted use, distribution, and reproduction in any medium, provided the original author and source are credited. 


\subsection{INSTALLATION OF LIGHTING COMPONENTS BASED ON MS ISO 303:2004}

\section{Specification of Lamp}

Based on the MS ISO 303:2004, a pair of lamps is located symmetrically to the longitudinal median plane of a vehicle. This assessment is not based on the edge of its illuminating surfaces; it is based on the exterior geometrical form of lights. Moreover, the lamps shall extend symmetrically to one another with the longitudinal median plane, excluding the interior structure of the lights. The lamp specifications require, similar colourimetric qualification to be met and with substantially identical photometric characteristics, for all fittings on vehicles. Table 1 shows the lighting components on the rear of HGVs that include direction indicator lamps (amber), stop lights (red), rear position lamps (red), and reversing lamps (white) (Malaysia Standard, 2011). The lamp colours of vehicles are as follows:

Table 1: Lighting components on the rear of heavy vehicles (Sources: MS ISO 303:2004)

\begin{tabular}{|c|c|c|}
\hline No. & Lamp & Colour \\
i. & Direction indicator lamp & Amber \\
ii. & Stop lamp & Red \\
iii. & Rear position lamp & Red \\
iv. & Reversing Lamp & White \\
\hline
\end{tabular}

\section{Warning System of Fog}

Variable message sign (VMS) can be automatically activated by the visibility sensors of the warning system. The advisory speed appears through VMS when a hazardous environment occurs due to the fog. A visibility sensor of fog detection and warning system is a point detection device that utilises infrared technology to measure visibility distance and VMS. When the visibility distance is critical $(<50 \mathrm{~m})$, the signing effects of visibility and VMS appear to be significant. By contrast, other categories of visibility distance are light fog (50-200 m) and good visibility (>200 m) (Al-ghamdi, 2007).

\section{Implementation of Un Regulations}

UN Regulations 6, 7, 23 and 38 are related to the lighting components on the rear of HGVs. As stated in UN Regulation 7, the front and rear position lamps, stop lamps, and end-outline marker lamps must be installed for motor vehicles and trailers. Rear position lamps indicate the presence of a vehicle that comes from the rear. Meanwhile, stop lights work to inform other road users from the rear of the vehicle where the driver is applying the service brake. Stop lamps on the rear of the vehicle are activated by the application of a retarder or a similar device. The intensities shall be determined with the filament lamps that regularly alight; the colour of the light emitted shall be red (UN, 2012).

The direction indicator for vehicles in the UN Regulation 6 can be defined as a device mounted on a motor vehicle or a trailer when conducted by the driver, signalling the latter's intention to change the direction in which the vehicle is proceeding. A safety function exists in the directional indicator lamp, and amber is the colour of the light emitted inside the field of the light distribution grid (UN, 2014). The reverse lamp for vehicles in UN Regulation 23 is designed to illuminate road users to the rear of vehicles. The reversing light (white lighting) is used for vehicles to move backwards, and warning other road users is crucial (UN, 2003).

The provision concerning the approval of rear fog lamps for certain power-driven vehicles and their trailers is stated in UN Regulation 38. The red light colour of rear fog lamps requires vehicles to be more conspicuous from the rear by giving a red signal of greater intensity (UN, 2013).

\subsection{LEGISLATION RELATED TO VEHICLES}

\section{The Road Transport Act 1987}

Based on the regulation, all commercial vehicles shall be routinely inspected every six months at the PUSPAKOM. At the routine inspection, the criteria of all the commercial vehicles must be checked to meet the standard or regulations to avoid road accidents. Moreover, PUSPAKOM can make a recommendation to improve the road safety of road users. As stated in the Road Transport Act 1987 Section 66, lights must be installed in motorised 
vehicles, in respect of the nature of such lights, the positions in which they shall be fixed and the periods during which they shall be lighted or otherwise.

\section{MATERIALS AND METHODS}

\subsection{STUDY AREA}

A site investigation was conducted to identify the rear marking availability and lighting components on the trucks and lorries in Malaysia. Lorries and trucks were observed at Jawi Toll Plaza in Nibong Tebal, Pulau Pinang, Malaysia (37²5'19.1"N $\left.122^{\circ} 05^{\prime} 06^{\prime \prime} \mathrm{W}\right)$, as illustrated in Fig. 1.

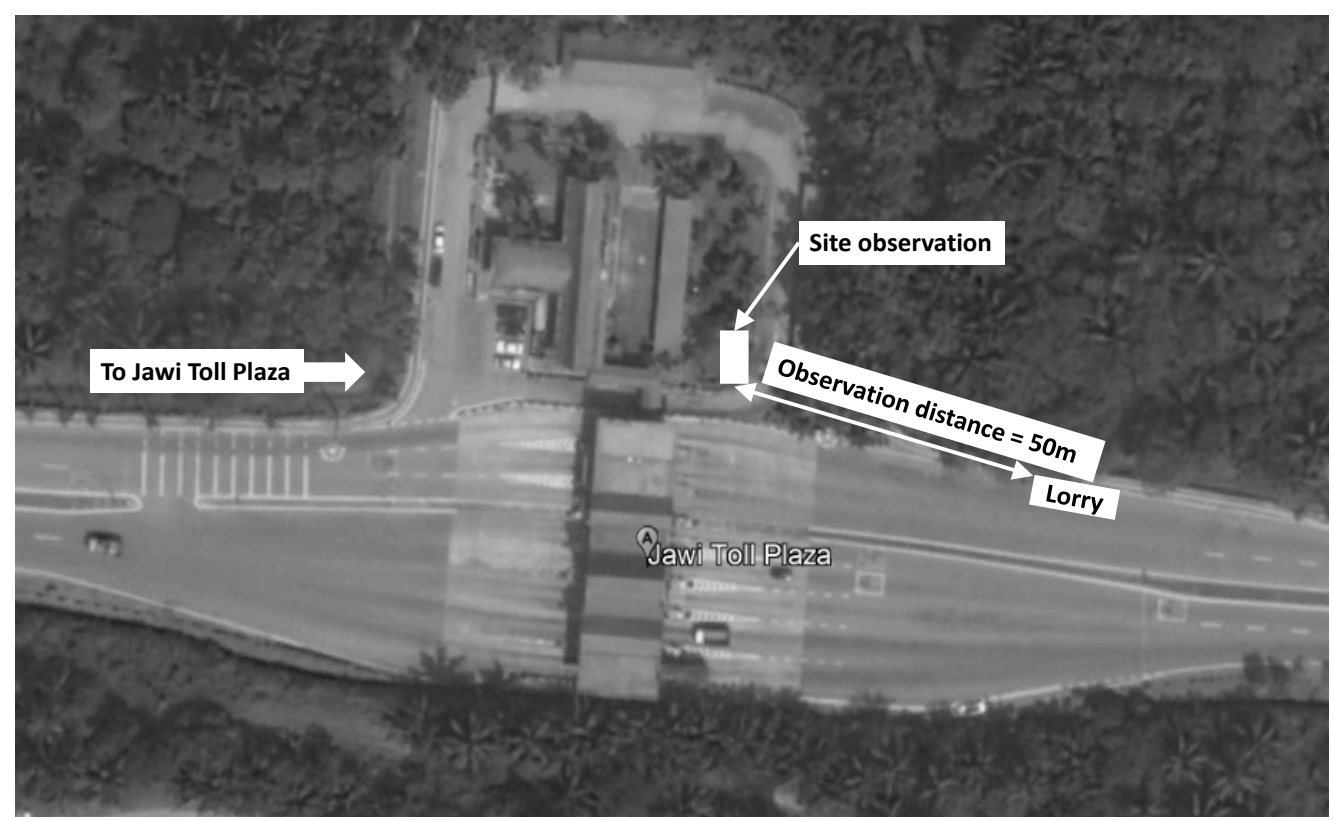

Figure 1: Jawi toll plaza in Nibong Tebal, Pulau Pinang

Approximately 830 lorries were observed, and data were categorised into seven vehicle types, namely; cargo semi-trailer, tank semi trailer, five-axle box truck, two-axle box truck, garbage truck, dumper tipper truck and cargo truck, as illustrated in Fig. 2.

1. Cargo Semi Trailer

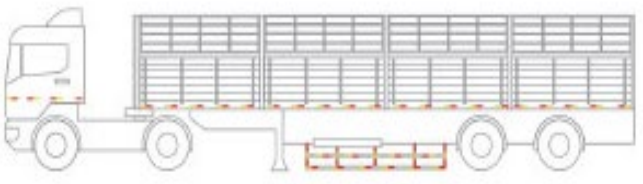

2. Petrol/ Diesel/ Oil/ Gas Tank Semi Trailer

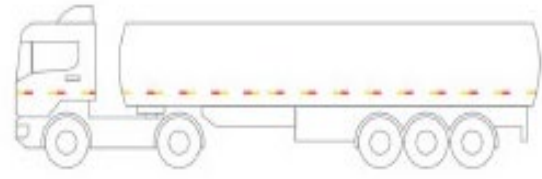

3. Box Truck 5 Axles

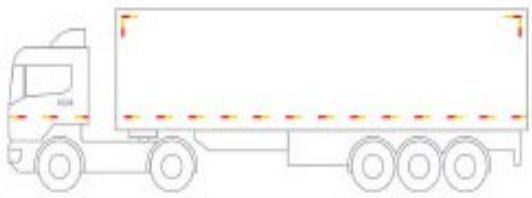

4. Box truck 2 Axles

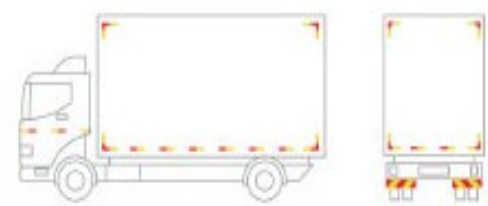

5. Garbage Truck
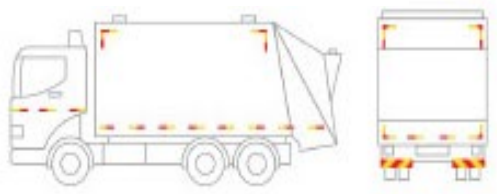

6. Dumper Tipper and Cargo Truck

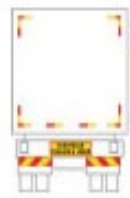

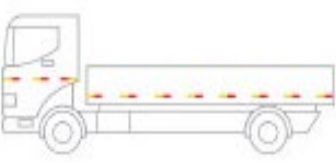

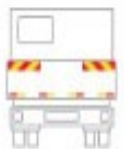

Figure 2: Types of HGVs (Sources: Tritech, 2015) 
A video camera was used to capture various commercial trucks from 9:00 a.m. to 5:00 p.m. The proper techniques for setting up, handling, and using tripods are listed below:

1) Firstly, the legs of the tripod should be adjusted to stand stably on the ground, and the tensioners on the legs of the tripod are released. Secondly, the legs of the tripod must be raised to a height of $1 \mathrm{~m}$ from the ground level, as illustrated in Fig. 3. Thirdly, the camera can be attached on the tripod. Most importantly, if the tripod legs must be extended, check that they are securely locked in place before mounting the camera.

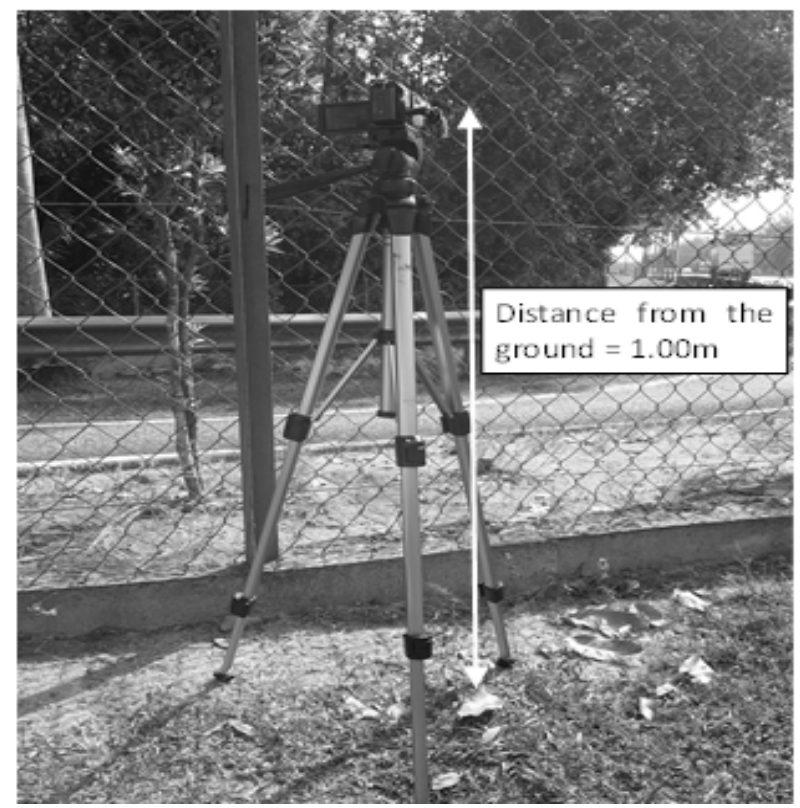

Figure 3: Height of the tripod

2) Screw the camera onto the tripod. The camera may be screwed directly onto the tripod and may need to be clamped in place. The screws should also be tightened to hold the camera steadily. The pieces must be twisted together until they are snugly joined.

3) The camera on the tripod should be able to swivel for pan shots, but the rig can always be moved to a convenient spot. Ensure that the tripod is level and stable when shooting. More than 850 samples of various lorries and trucks were collected randomly at Jawi Toll Plaza. The observation distance between the camera and the rear of the heavy goods vehicle was approximately $50 \mathrm{~m}$, as displayed in Fig. 4.

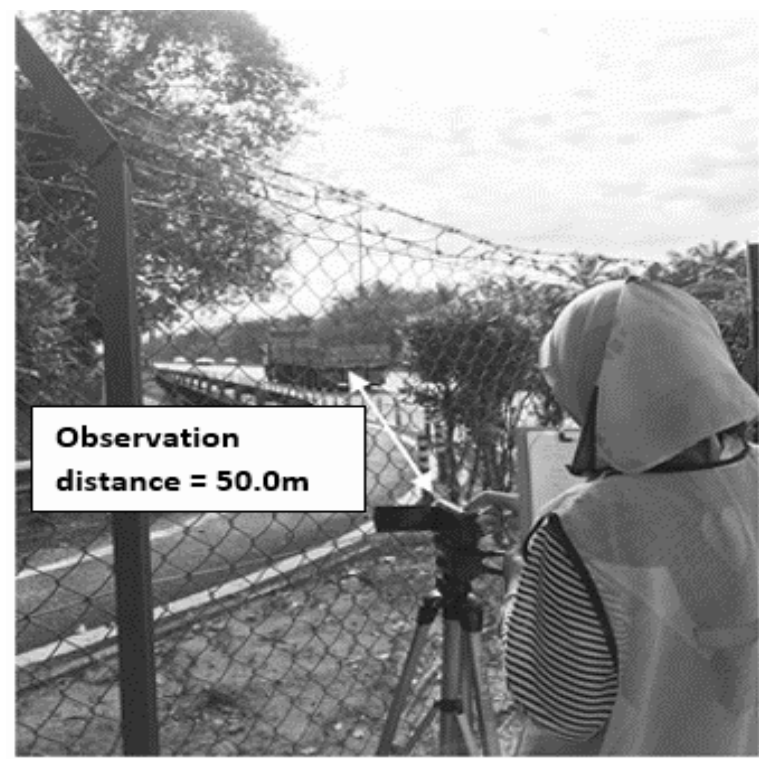

Figure 4: Observation distance between the camera and the truck 


\subsection{DATA ANALYSIS}

The analysed data of the lighting components on HGVs were based on the data recorded as $N P$ and $N$, as shown in Equation (1). More than 830 samples of various lorries and trucks were collected randomly at Jawi Toll Plaza. The compliance rate on the number of installations of lighting components was compliant to MS ISO 303:2004.

\subsection{LIGHTING COMPONENTS}

Percentage of lighting components $(\%)=\frac{N P}{N} \times 100 \%$,

Where

$N P=$ number of lorries that pass the lighting components

$N=$ total number of lorries

Example using Equation (1) for cargo semi-trailers for stop lamps:

Percentage of lighting components $(\%)=\frac{N P}{N} \times 100 \%$

$$
\begin{aligned}
& =\frac{96}{100} \times 100 \% \\
& =96 \%
\end{aligned}
$$

\subsection{COMPLIANCES}

Percentage of lighting compliance $(\%)=\frac{N C}{N} \times 100 \%$,

Where

$N C=$ number of lorries that comply with the lighting components

$N=$ total number of lorries

Example using Equation 2 for cargo semi-trailers that comply with the lighting components:

$$
\begin{gathered}
\text { Percentage of lighting compliance }(\%)=\frac{N C}{N} \times 100 \% \\
=\underline{78} \times 100 \% \\
=780
\end{gathered}
$$

The data were then gathered and analysed according to the objectives of this study. Descriptive analyses were conducted to obtain the distributions and profiles of the data having outcomes, which suggest recommendations that can reduce the number of rear-end and under ride collisions involving heavy vehicles, particularly those related to conspicuity issues.

\section{RESULTS AND DISCUSSIONS}

\subsection{LIGHTING COMPONENTS}

In Malaysia, all vehicles must be equipped with lighting components on the rear of heavy vehicles. Based on the MS ISO 303:2004 (Figure 5), direction indicator lamps, stop lamps, rear position lamps and reversing lights are considered lighting components. If HGVs are not equipped with these four lighting components, then such vehicles are considered not complying with the standard. The measured height above the ground has two categories, namely, the maximum height (H1) and the minimum height (H2). H1 is measured from the highest point of the apparent surface in the direction of the reference axis, whereas the $\mathrm{H} 2$ is measured from the lowest point. 


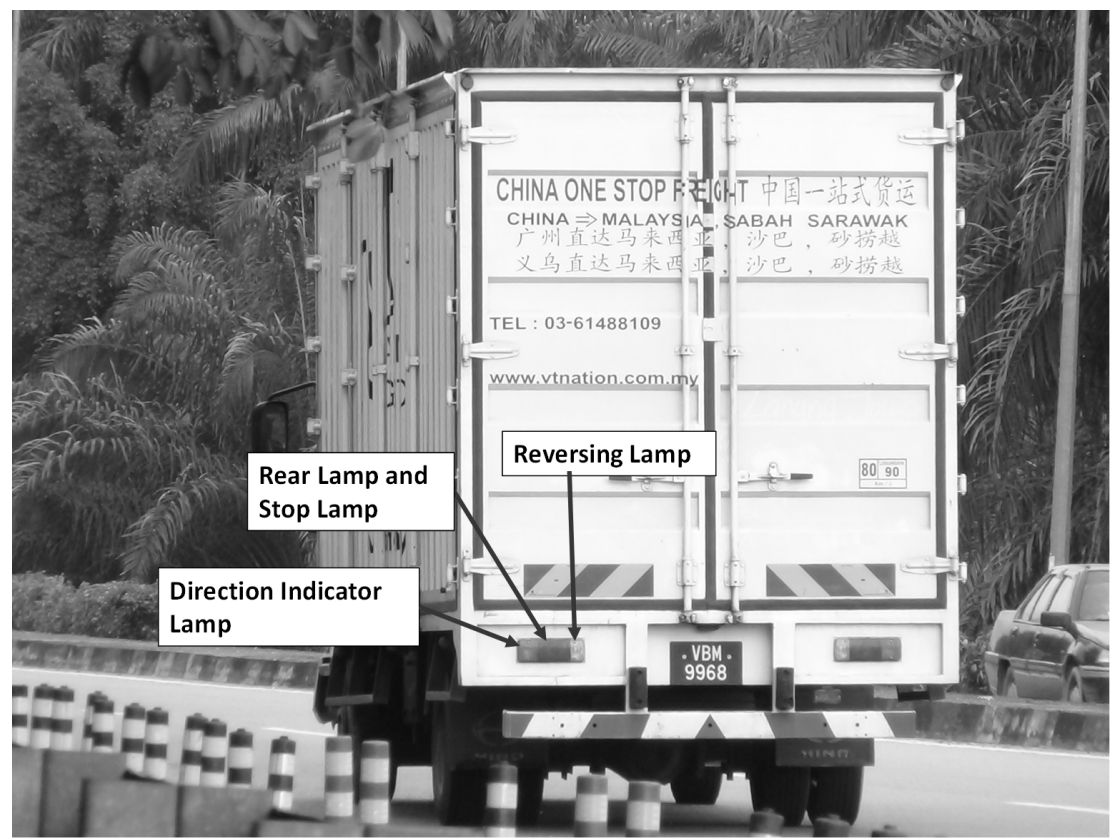

Figure 5: Lighting components on the truck

Table 2: Lighting components on HGVs

\begin{tabular}{|c|c|c|c|c|c|c|c|c|}
\hline \multirow[t]{2}{*}{ No. } & \multirow{2}{*}{$\begin{array}{c}\text { Sample, } \\
\mathrm{N}\end{array}$} & \multirow[t]{2}{*}{ Lorry Types } & \multicolumn{4}{|c|}{ Lighting Components } & \multicolumn{2}{|c|}{ Compliance } \\
\hline & & & $\begin{array}{l}\text { Rear } \\
\text { Lamp }\end{array}$ & $\begin{array}{l}\text { Stop } \\
\text { Lamp }\end{array}$ & $\begin{array}{l}\text { Rear Direction } \\
\text { Indicator Lamp }\end{array}$ & $\begin{array}{l}\text { Reversing } \\
\text { Lamp }\end{array}$ & Comply & $\begin{array}{c}\text { Not } \\
\text { Comply }\end{array}$ \\
\hline 1. & 100 & $\begin{array}{l}\text { Cargo Semi } \\
\text { Trailer }\end{array}$ & $\begin{array}{c}100 \\
100 \%\end{array}$ & $\begin{array}{c}96 \\
96 \%\end{array}$ & $\begin{array}{c}100 \\
100 \%\end{array}$ & $\begin{array}{c}79 \\
79 \%\end{array}$ & $\begin{array}{c}78 \\
78 \%\end{array}$ & $\begin{array}{c}22 \\
22 \%\end{array}$ \\
\hline \multicolumn{3}{|c|}{ Percentage (\%) } & & & & & & \\
\hline 2. & 50 & $\begin{array}{c}\text { Petrol/ Diesel/ } \\
\text { Gas Tank Trailer }\end{array}$ & 50 & 48 & 50 & 43 & 42 & 8 \\
\hline \multicolumn{3}{|c|}{ Percentage $(\%)$} & $100 \%$ & $96 \%$ & $100 \%$ & $86 \%$ & $84 \%$ & $16 \%$ \\
\hline 3. & 100 & Box Truck 5 Axles & 100 & 99 & 100 & 92 & 91 & 9 \\
\hline \multicolumn{3}{|c|}{ Percentage (\%) } & $100 \%$ & $99 \%$ & $100 \%$ & $92 \%$ & $91 \%$ & $9 \%$ \\
\hline 4. & 250 & Box Truck 2 Axles & 250 & 250 & 250 & 233 & 233 & 17 \\
\hline \multicolumn{3}{|c|}{ Percentage (\%) } & $100 \%$ & $100 \%$ & $100 \%$ & $93 \%$ & $93 \%$ & $7 \%$ \\
\hline 5. & 30 & Garbage Truck & 30 & 30 & 30 & 12 & 12 & 18 \\
\hline \multicolumn{3}{|c|}{ Percentage (\%) } & $100 \%$ & $100 \%$ & $100 \%$ & $40 \%$ & $40 \%$ & $60 \%$ \\
\hline 6. & 250 & Cargo Truck & 250 & 250 & 248 & 178 & 178 & 72 \\
\hline \multicolumn{3}{|c|}{ Percentage $(\%)$} & $100 \%$ & $100 \%$ & $99 \%$ & $71 \%$ & $71 \%$ & $29 \%$ \\
\hline 7. & 50 & $\begin{array}{c}\text { Dumper Tipper } \\
\text { Truck }\end{array}$ & 50 & 50 & 50 & 19 & 19 & 31 \\
\hline \multicolumn{3}{|c|}{ Percentage (\%) } & $100 \%$ & $100 \%$ & $100 \%$ & $38 \%$ & $38 \%$ & $62 \%$ \\
\hline
\end{tabular}

\subsection{LIGHTING COMPONENTS ON HGVS}

An investigation was performed to analyse the percentage of lighting components on the rear of HGVs based on the MS ISO 303:2004. The investigation data identified the lamps by function, and colours were effective. Presence lamps should be placed on the rear part, stop lamps must be red, direction indicator lamps should be amber, and reversing lamps must be white.

Figure 6 shows that all HGVs in Malaysia have rear lamps, suggesting 100\% rear lighting components. Besides, dumper trucks contribute the lowest percentage among other trucks, only $38 \%$ of which are equipped with reversing 
lights. Dumper trucks have the lowest recorded percentage of reversing lamp instalments among the other trucks. Reversing lamps are critical because they alert other road users when the trucks are about to perform a reverse.

The highest percentage of lighting components on trucks that complied with the standard was approximately 93\%, referring to the lighting components on two-axle box trucks, as illustrated in Figure 7. At the same time, the highest percentage of lighting components on dumper trucks that failed to meet the requirement was approximately $62 \%$. This observation showed the design of rear lamps on dumper trucks, which was unable to meet the light regulations. Berces (2011) stated that based on the UN Regulation 48, lighting and light-signalling devices must be installed in the rear and side of HGVs for visibility requirements.

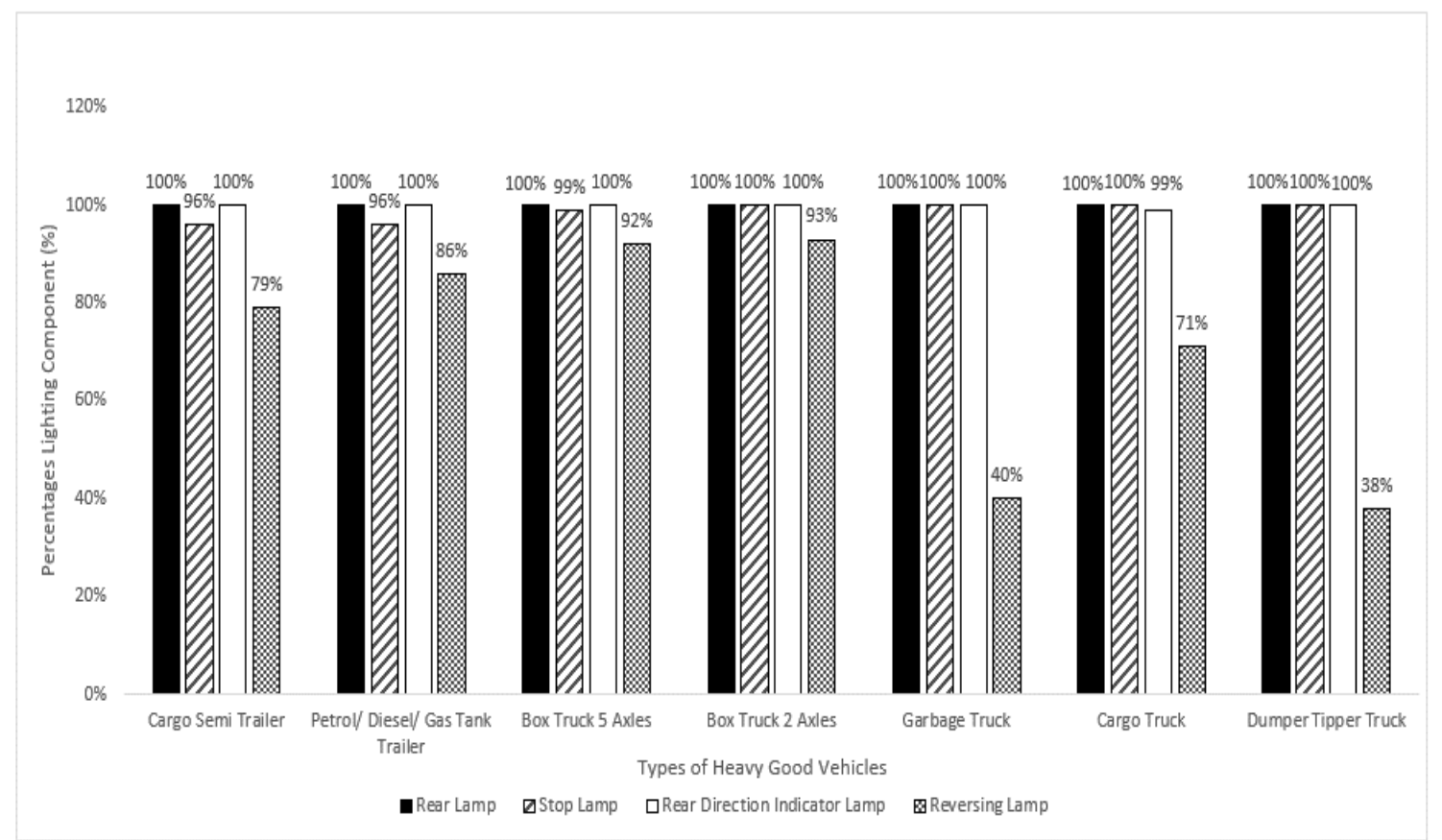

Figure 6: Percentages of lighting components

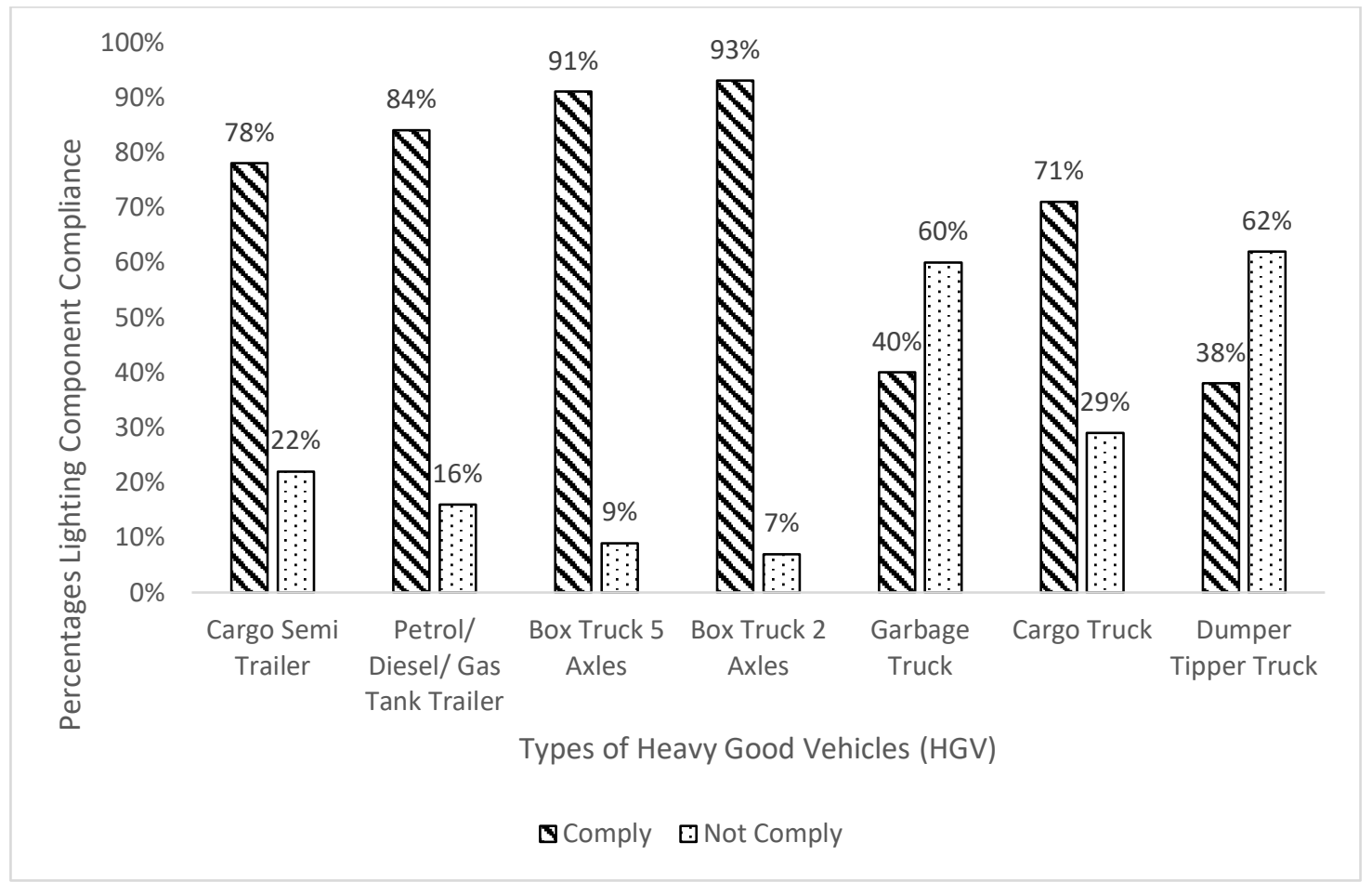

Figure 7: Percentages of lighting component compliances 


\section{CONCLUSIONS AND RECOMMENDATIONS}

This study investigated the percentages of lighting components that comply with MS ISO 303:2004. Based on the observation at the selected site, $93 \%$ of two-axle box trucks had installed rear lighting components that adhere to the standard compared with other HGVs between $38 \%$ and $91 \%$, both of which should improve. In conclusion, albeit the high compliance level of the rear lighting components, the type of crash involved is based on inadequate visibility when running vehicles come into the rear or side of slowly moving or stationary vehicles at night. Moreover, vehicles rear-end collisions tend to occur during bad weather conditions. The crashes mostly happen at the rear end of trucks, which lack conspicuity on dark unlit roads.

\section{SOURCES OF FUNDING}

None.

\section{CONFLICT OF INTEREST}

None.

\section{ACKNOWLEDGMENT}

This work is self-funded by the EACAR, Universiti Sains Malaysia. We express our gratitude to the Road Transport Department (JPJ) Seberang Jaya, Pulau Pinang Malaysia.

\section{REFERENCES}

[1] Al-Ghamdi, A. S. Experimental Evaluation of Fog Warning System, Accident Analysis \& Prevention. 39(6), 2007, 1065-1072.

[2] Ashedenden \& Associates, P.C. The Different Types of Trucking Accidents. 2018, Available from: < https://www.ashendenlaw.com/the-different-types-of-trucking-accidents/>. [Accessed on: 12 March 2019].

[3] Kirkendall, A. Underride Accidents. n.d., Available from:<http://kirkendalldwyer.com/areas-ofpractice/motor-vehicle-accidents/truck-accident/underride-accidents/>. [Assessed on: 28 February 2019].

[4] Malaysian Standard. Road Vehicles- Installation of Lighting and Light-Signalling Devices for Motor Vehicles and their Trailers, MS ISO 303:2002, Department of Standards Malaysia. 2011.

[5] Road Transport Act. Law of Malaysia, Part II - Classification, Registration and Licensing of Motor Vehicles and Drivers, Section 66. 1987.

[6] Tritech. MS828:2011 SIRIM Certified Commercial Vehicles Rear \& Side Markings - Light Reflectors. 2015, Available from: <http://www.tritech.com.my/main/list/ms8282011-sirim-certified-commercial-vehiclesrear-amp-side-markings---light-reflectors-253>. [Accessed on: 22 September 2020].

[7] United Nations. Addendum 22: Regulation No. 23 Uniform Provisions Concerning the Approval of Reversing Lamps for Power-driven Vehicles and their Trailers. 2003.

[8] United Nations. Addendum 6: Regulation No. 7 Uniform provisions concerning the approval of front and rear position lamps, stop lamps and end-outline marker lamps for motor vehicles (except motorcycles) and their trailers. 2012.

[9] United Nations. Addendum 37: Regulation No. 38 Uniform provisions concerning the approval of rear fog lamps for power-driven vehicles and their trailer. 2013.

[10] United Nations. Addendum 5: Regulation No. 6 Uniform provisions concerning the approval of direction indicators for power-driven vehicles and their trailers. 2014 